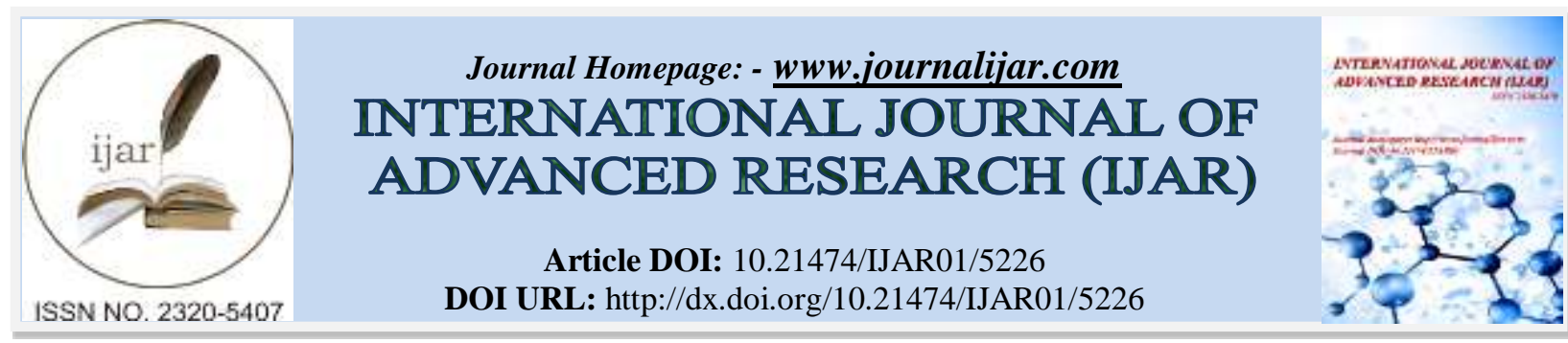

RESEARCH ARTICLE

\title{
THE UTILITY OF GOLD NANOPARTICLES AS AN EFFECTIVE DRUG CARRIER AND ITS ANTIBACTERIAL EFFICACY WITH GEMIFLOXACIN HCL.
}

\author{
Amira S. Eldin', "Shereen M. Azab", Abdallah A. Shalaby ${ }^{2}$ and Magda El-Maamly². \\ 1. Pharmaceutical Chemistry Dept., National Organization for Drug Control and Research [NODCAR], 6 Abu \\ Hazem Street, Pyramids Ave, P.O. Box 29, Giza, Egypt. \\ 2. Department of Analytical Chemistry, Faculty of Pharmacy, Zagazig University, P.C.44 519, Zagazig, Egypt.
}

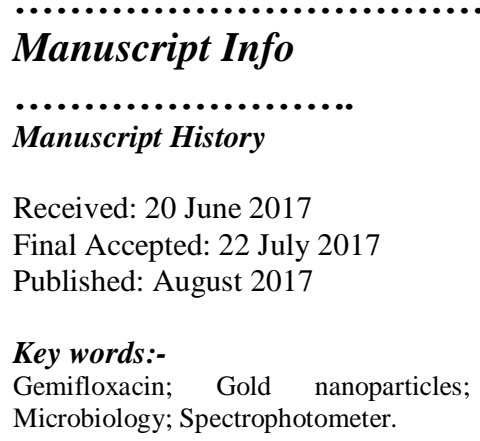

\begin{abstract}
A simple and extractive spectrophotometric method was developed for the determination of Gemifloxacin $\mathrm{HCl}$ (GEM) in bulk drug and pharmaceutical formulation. The method depends on the reaction between Gemifloxacin and gold nanoparticles (AuNps). The apparent molar absorptivity and Sandell's sensitivity were found to be $0.1 \times 10^{4}$ $\mathrm{L} \mathrm{mol}^{-1} \mathrm{~cm}^{-1}$ and $0.0038 \mu \mathrm{g} \mathrm{cm}^{-2}$ respectively. Beer's law was conformed in the concentration range of $1.5-38.8 \mu \mathrm{g} \mathrm{mL}^{-1}$. The method is very simple and not time consuming, therefore it can be properly applied for the evaluation of Gemifloxacin in dosage forms and also in vitro antibacterial activities of GEM, gold nanoparticles and drug coated gold nanoparticles against several strains of Gram positive and Gram negative organisms. The antibacterial properties of GEMAuNps complex were higher than that of the pure Gemifloxacin while gold nanoparticles did not produce any antibacterial activity against the bacterial strains. These results recommend that gold nanoparticles could act as an effective drug carrier in drug delivery system.
\end{abstract}

Copy Right, IJAR, 2017,. All rights reserved.

\section{Introduction:-}

Gemifloxacin mesylate (GEM) is chemically 7-[(4Z)-3-(aminomethyl)-4-methoxyimino-pyrrolidin-1-yl]-1cyclopropyl-6-fluoro-4-oxo-1,4 dihydro -1,8-napththyridine-3-carboxylic acid, a fluoroquinolone antibacterial drug towards bacterial topoisomerase IV. It is used for the curing of chronic bronchitis and urinary tract infection (Krishna and Sankar, 2008; Lowe and Lamb, 2000; Lomaestro, 2000). Numerous analytical techniques for GEM estimation including HPLC-tandem mass spectrometry (Doyle et al 2000), RP-HPLC and HPTLC (Rote and Pingle,2009), microchip electrophoresis (Cho et al 2004) in human plasma, RP-HPLC (Vinodhini et al 2009) and ion-pair complex (Krishna and Sankar, 2008) for tablet formulation. UV spectrophotometric methods, alternatively, provides economic processes, which are less time consuming and more sensitive compared to the RP-HPLC method.

Gold nanoparticles (AuNps) have bio-applications in different areas like drug delivery and sensing (Chen et al 2007; Jalil and Nixon, 1990). Optical properties of AuNps change when they interact with certain molecules, allowing the detection of analytes. Absorption spectra of AuNps change significantly when several particles combine with them (Arulkumar and Sabesan , 2010). AuNps exhibit excellent biocompatibility and unique structural and catalytic attributes which have made them a very attractive material for sensors and electrocatalyst (Atta, Galal and Azab, 2012; Salama et al 2016; Atta, Galal and Azab, 2012; Atta, Galal and Azab, 2011. AuNps are emerging as 
significant type of colorimetric reporter (Brust et al 1995; Mirkin et al 1996; Demers et al 2000; Kim, Johnson and Hupp 2001) formation with AuNps lead to a distinct change in color. In certain new reports; AuNps are used as a detection probe for the anticancer drugs (Selvaraj, Alagar and Hamerton, 2006), however no quantification has been carried out up to now. We report here a plan for drug detection and quantification by gold nanoparticles. The chromatographic methods are time consuming, expensive and require proficiency while, for the routine analysis, a simple, fast and cost effective analytical method is required and favored. UV-spectrophotometric method can be used for routine investigation of raw materials and pharmaceutical formulations (Sharada, Channabasavaraj and Mani , 2014; Menon et al 2012). The impartial of this study is to progress a simple analytical method with a wide detection range for the determination of GEM in bulk and pharmaceutical formulations.

\section{Materials and methods:- \\ Materials:-}

All solutions were prepared and diluted with distilled water. GEM was obtained from Hikma Pharm (Egypt). Factive tablets (Memphis) labeled to contain $320 \mathrm{mg}$ gemifloxacin per tablet. Hydrogen tetrachloroaurate $\mathrm{HAuCl}_{4}$ and trisodium citrate were obtained from sigma Aldrich.

\section{Instrument:-}

The spectrophotometric measurements were carried out using Shimadzu (UV-1601) UV- Visible spectrophotometer with quartz cells of $1 \mathrm{~cm}$ optical length incorporated with a pc computer. TEM image was performed by JEM-2100 (high-resolution transmission electron microscope).

\section{Synthesis of gold nanoparticle:-}

AuNps were prepared by adding trisodium citrate to a boiling $1 \mathrm{mM} \mathrm{HAuCl}{ }_{4}$ solution, turning the yellow gold chloride into red wine color (Atta, Galal and Azab, 2012). The solution was stored at $4{ }^{\circ} \mathrm{C}$ and a characteristic peak in the UV-vis spectrum at $522 \mathrm{~nm}$ for AuNps was obtained.

\section{Preparation of GEM tablets:-}

Accurately weighed amount of the finely powdered tablets equivalent to $19.5 \mathrm{mg}$ of the drug salt was dissolved in distilled water, the mixture was agitated by an electrical shaker for about $10 \mathrm{~min}$. This solution was filtered and completed to $50-\mathrm{mL}$ with distilled water. More dilute solutions were prepared whenever required and analyzed by the subsequent procedures.

\section{Details of microbial assay:-}

The antibacterial activities study was performed by the standard disc diffusion method against the different standard bacterial strains according to Clinical and Laboratory Standards Institute (CLSI 2013) guidelines. Three to five wellisolated bacterial colonies were touched with a sterile loop from an overnight agar plate culture and moved into 5 $\mathrm{mL}$ of brain heart infusion broth. The broth culture was incubated at $37^{\circ} \mathrm{C}$ with shaking for 4 to 6 hours until it reaches or exceed the turbidity of a $0.5 \mathrm{McFarland}$ standard. This results in a suspension containing approximately 1 $\times 10^{8} \mathrm{CFU} / \mathrm{mL}$. A sterile cotton swab was immersed into the inoculum. The swab was streaked over the whole surface of the Mueller Hinton agar plate and around the rim of the agar. The plates were left for 3-5 minutes. $8 \mu \mathrm{L}$ of AuNps, GEM and the complex were applied respectively to each sterile disk and dried in sterile laminar flow cabinet before used. The disks were placed on the inoculated Mueller Hinton agar plates with sterile forceps. The discs were arranged at $15 \mathrm{~mm}$ from edge of the Petri dish and $30 \mathrm{~mm}$ from each other to decrease overlapping zones. Inoculated plates were incubated inverted within 15 minutes of disk application at $37{ }^{0} \mathrm{C}$ for 24 hours.

\section{Results and discussion:-}

\section{Characterization of GEM-AuNps:-}

The morphology of AuNps was determined using TEM (fig 1A). Particles are aggregate in irregular shape with average diameter of $\approx 43 \mathrm{~nm}$. The UV-vis spectrum of GEM, AuNps and GEM-AuNps complex in aqueous solution show absorption maximum at 211, 522 and $650 \mathrm{~nm}$ respectively (fig. 1B). The color change of AuNps from wine red to dark blue on the addition of GEM confirms the interaction between the drug and nanoparticles. Pure drug displays a maxima at $211 \mathrm{~nm}$ due to $\mathrm{n}-\pi^{*}$ and $\pi-\pi *$ transition of GEM molecule. After the addition of AuNps, the intensity of both bands of GEM and AuNps due to the electrostatic interaction between them and a new peak was observed at $650 \mathrm{~nm}$. The appearance of a new peak is due to the aggregation (Selvaraj and Alagar, 2007) of GEM on AuNps, which resulted in the additional band at longer wavelength. 

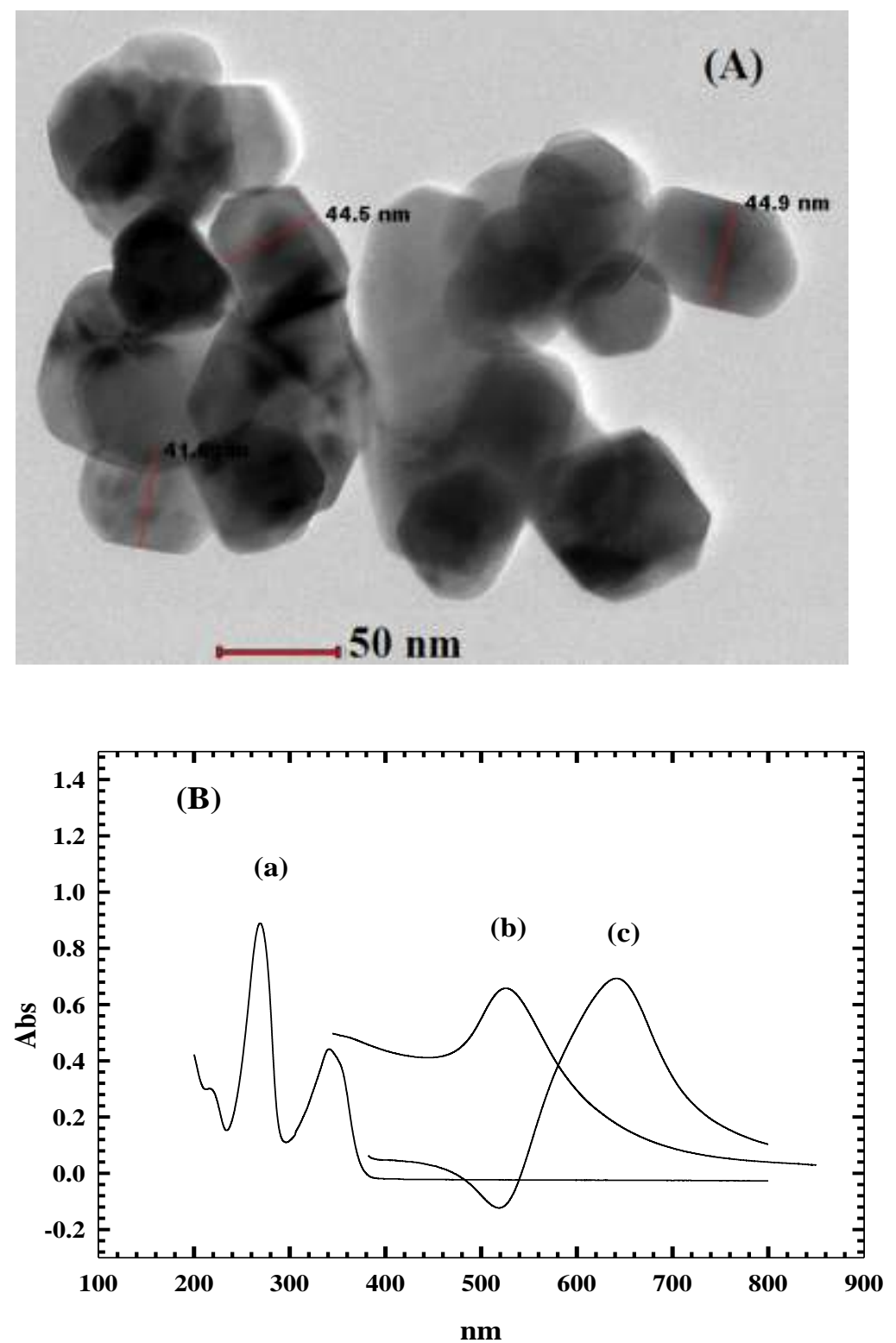

Fig.1:- (A) TEM image AuNps. (B) UV overlay graph of a) GEM, b) AuNps and c) GEM-AuNps complex.

The mechanism of GEM aggregation on AuNps is represented in Schematic 1. The colloidal solution containing citrate-capped AuNps has very intense and characteristic wine red color arising from the ordered electronic motion, which gives the absorption value at $522 \mathrm{~nm}$ in the UV-vis. spectrum. After the addition of GEM; a quenching of the characteristic absorption band which follows a shift to the longer wavelength was observed. 


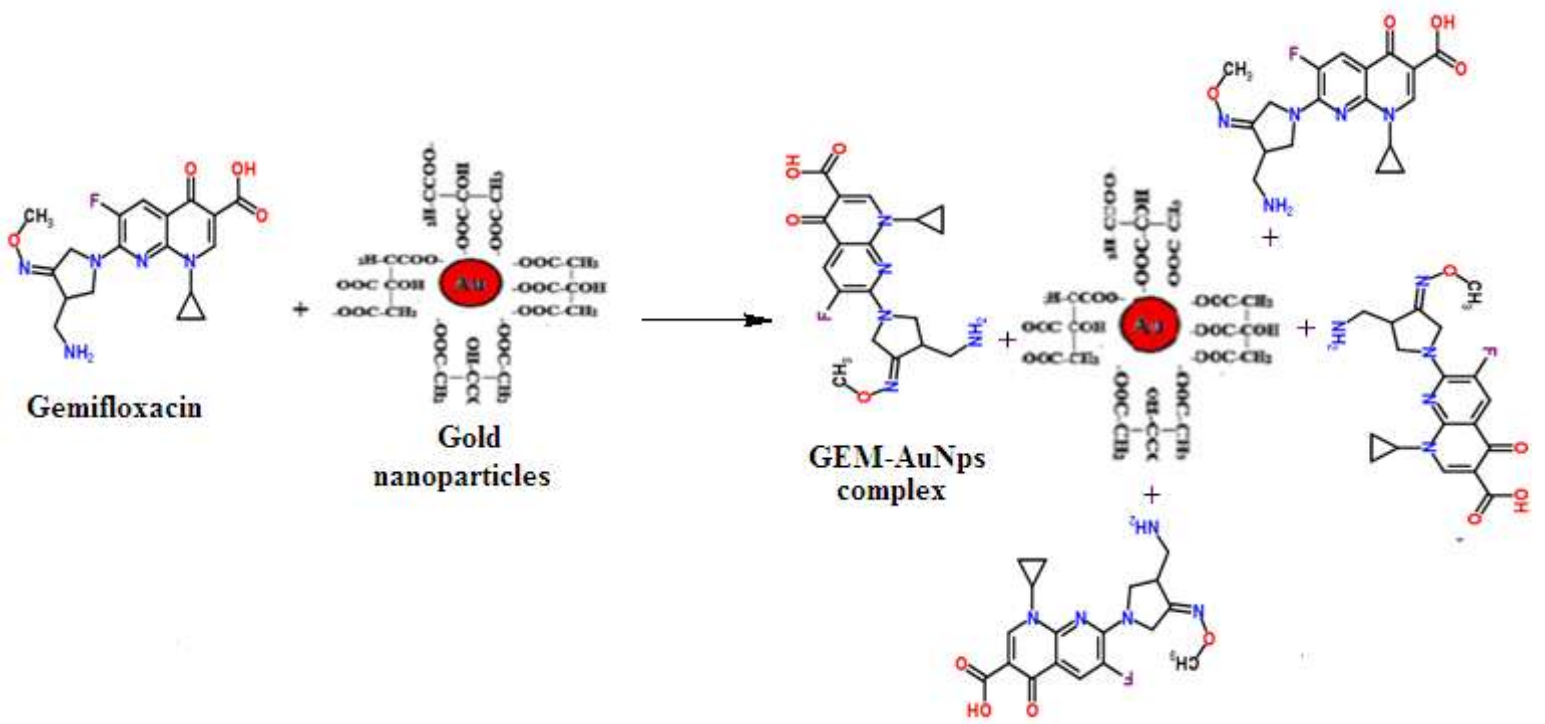

Scheme 1:- Schematic diagram of elucidating the aggregation of GEM on gold nanoparticles.

\section{Optimum conditions for drug determination:-}

Effect of time and temperature:-

The formation of the complex is rapid and the absorbance readings were constant after $10 \mathrm{~min}$ and were stable for at least $1 \mathrm{hr}$. Shaking time ranging from 0.5 to $5.0 \mathrm{~min}$ did not produce any change in color intensity, and so $1 \mathrm{~min}$ shaking time was selected. The influence of temperature on the complex was examined by measuring the absorbance values at different temperatures. It was found that the absorbance was stable up to $35{ }^{\circ} \mathrm{C}$, therefore all subsequent studies were carried out at room temperature $\left(25 \pm 1^{\circ} \mathrm{C}\right)$.

\section{Effect of solvent:-}

The type of solvent employed affects both wavelength and intensity of the maximum absorption. The effect of distilled water, methanol, dichloromethane, 1,2 dichloroethane, acetone and dioxane at a fixed wavelength was studied. As shown in figure 2 , distilled water gives the highest absorbance peak of the complex.

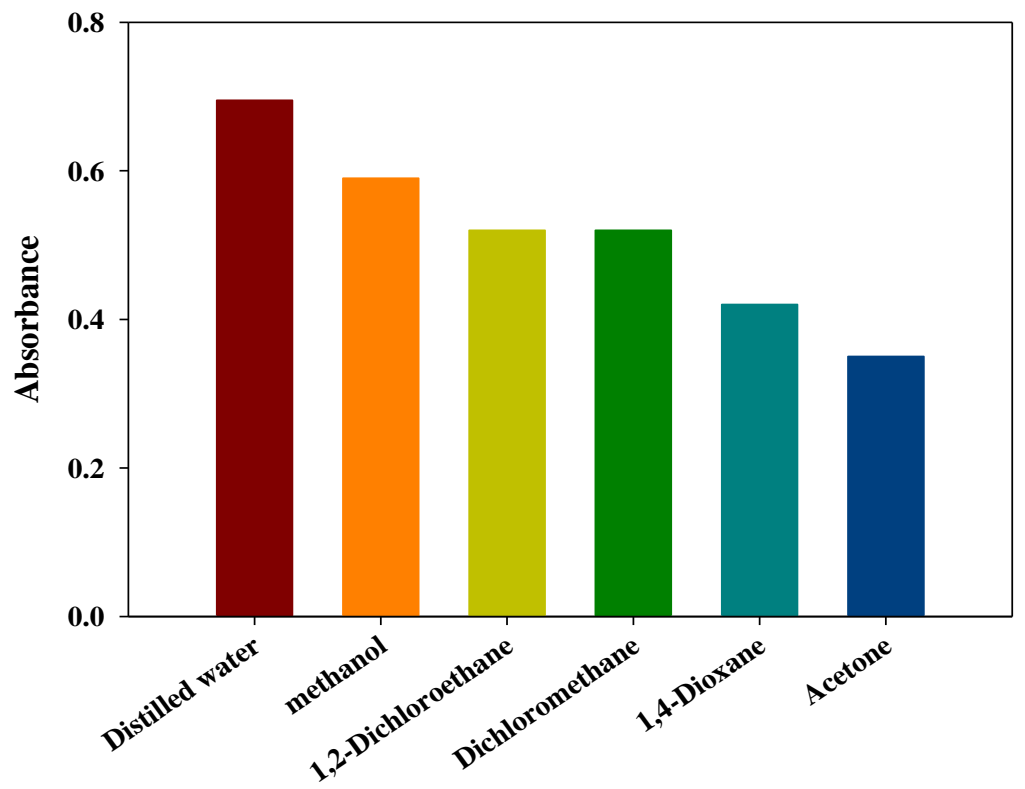

Fig. 2:- Effect of different solvents on the absorption intensity of reaction product of GEM-AuNps complex. 


\section{Effect of reagent concentration:-}

The effect of reagent was studied by measuring the absorbance of solutions containing a fixed concentration of (GEM) and varied amounts of the reagent. Maximum color intensity of the complex was achieved with $2.0 \mathrm{ml}$ of $1 \times 10^{-3} \mathrm{M}$ of reagent solution (fig $\left.3 \mathrm{~A}\right)$.

Stoichiometry of the complex:-

a) Continuous variation method:-

The composition of complex was established by Job's method of continuous variation (Job, 1928). Continuous variation method of $1.0 \times 10^{-3} \mathrm{~mol} \mathrm{~L}^{-1} \mathrm{GEM}$ and $1.0 \times 10^{-3} \mathrm{~mol} \mathrm{~L}^{-1}$ AuNps was performed. A series of solutions were organized in which the total volume of drug and reagent was kept constant at $1 \mathrm{~mL}$, diluted to the volume in $5 \mathrm{~mL}$ measuring flask with distilled water and the total molar concentration was $2 \times 10^{-4} \mathrm{M}$. The relation between absorbance and mole fraction of reagent is represented in figure $3 \mathrm{~B}$, indicating that the composition of the complex of GEM with AuNps was found to be 4:1 complex.

\section{b) Molar ratio method:-}

A series of solutions were prepared in which the concentration of AuNps was kept constant at $1 \times 10^{-4} \mathrm{~mol} \mathrm{~L}^{-1}$ while the drug concentration varied from $1 \times 10^{-4}-6 \times 10^{-4} \mathrm{~mol} \mathrm{~L}^{-1}$. The absorbances of the resulting solutions were measured at $650 \mathrm{~nm}$. The relationship (fig 3C) represented by two straight lines exhibiting one break at the molar ratio of 4:1 for AuNps with GEM. These results are similar with those obtained from the continuous variation method.
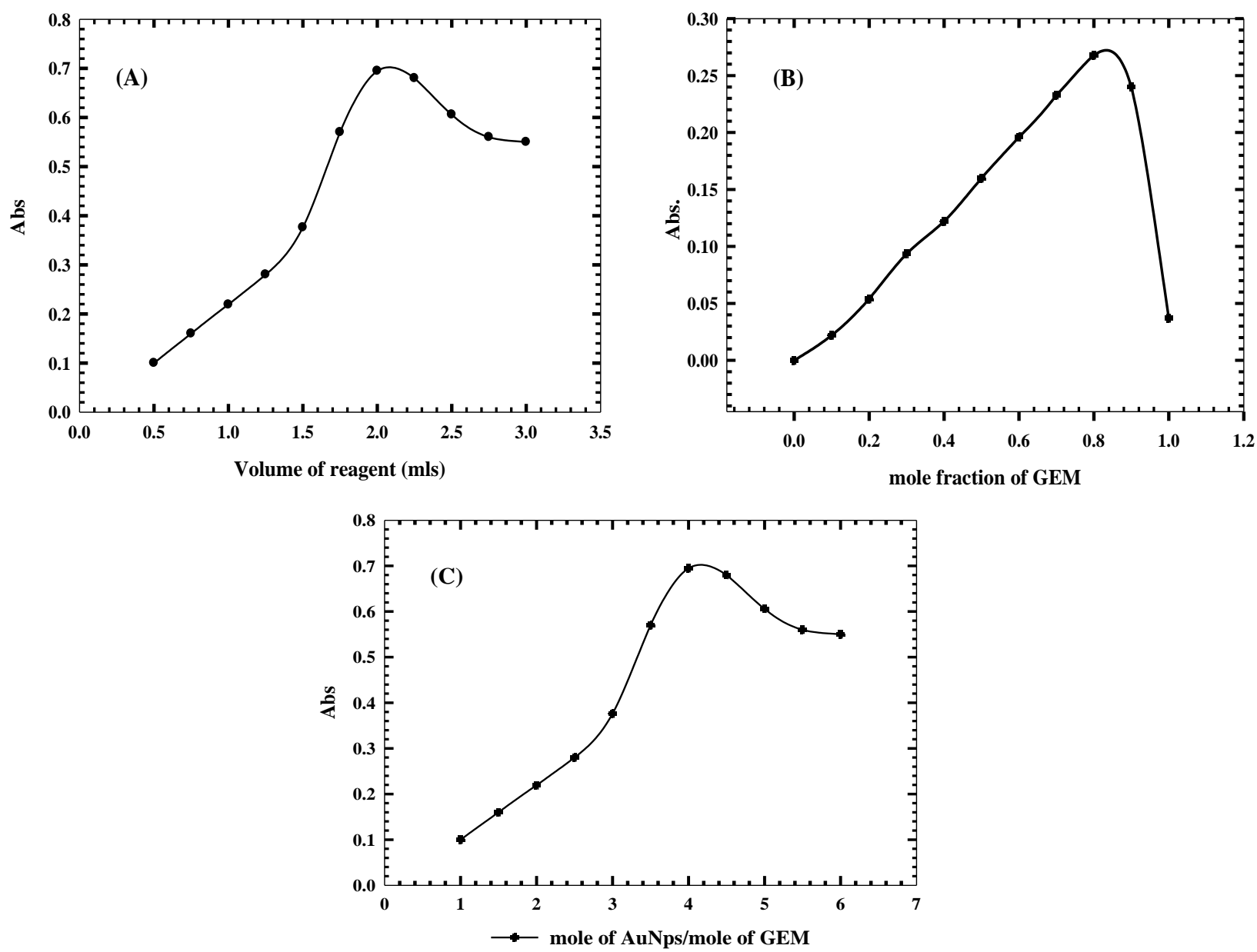

Fig.3: A):- Effect of concentration of reagent on the absorbance of complex of $38.8 \mu \mathrm{g} \mathrm{mL}^{-1} \mathrm{GEM}_{\text {with AuNps. B) }}$ Continuous variation plot for complex of: GEM with AuNps. C) Molar ratio of AuNps-GEM complex. 


\section{Conditional stability constant of GEM -AuNps complex:-}

The conditional stability constant $\left(\mathrm{K}_{\mathrm{f}}\right)$ of the complex of GEM with AuNps under the experimental conditions described above was calculated from the continuous variation data using the following equation (Sommer, Havel and Kubáň, 1970).

$$
\mathbf{K}_{\mathbf{f}}=\frac{A / A_{m}}{\left[1-\left(A / A_{m}\right)\right]^{n+1} G_{M}{ }^{n}(n)^{n}}
$$

Where $\mathrm{A}$ is the maximum absorbance of the complex and $\mathrm{A}_{\mathrm{m}}$ is the absorbance value when all the drug present is completely associated which corresponding to intersection of the two tangents of the curve. $C_{M}$ is the mole concentration of drug at the maximum absorbance and $\mathrm{n}$ is the stoichiometry with which drug is associated with AuNps. The formation constant value $\left(\mathrm{K}_{\mathrm{f}}\right)$ of complex was calculated to be $1.12 \times 10^{19} \mathrm{~L} / \mathrm{mole}$.

The standard free energy, $\Delta \mathrm{G}^{0}$ of complexation is related to the formation constant $\left(\mathrm{K}_{\mathrm{f}}\right)$ by:

$\Delta \mathrm{G}^{0}=-2.303 \mathrm{R} \mathrm{T} \log \mathrm{K}_{\mathrm{f}}$

Where $\Delta \mathrm{G}^{\mathrm{o}}$ is the free energy change of the complex $\left(\mathrm{Kcal}_{\mathrm{mol}}{ }^{-1}\right), \mathrm{R}$ is the gas constant $\left(1.987 \mathrm{cal} \cdot \mathrm{mol}^{-1} \cdot \mathrm{deg}^{-1}\right), \mathrm{T}$ the temperature in Kelvin $\left(273+25^{\circ} \mathrm{C}\right)$ and was found to be $26.08 \mathrm{Kcal} \mathrm{mol}^{-1}$.

\section{Method development and validation:-}

The linearity was determined by plotting various concentrations of GEM in the range of $1.5-38.8 \mu \mathrm{g} \mathrm{mL} \mathrm{m}^{-1}$ versus the absorbance (fig 4). The limit of detection (LOD) and the limit of quantification (LOQ) were calculated according to the $3.3(\sigma / \mathrm{S})$ and $10(\sigma / \mathrm{S})$ respectively (Atta et al 2015) where $\sigma$ is the standard deviation of intercept of regression equation and $\mathrm{S}$ is the slope of the corresponding calibration curve (inset).

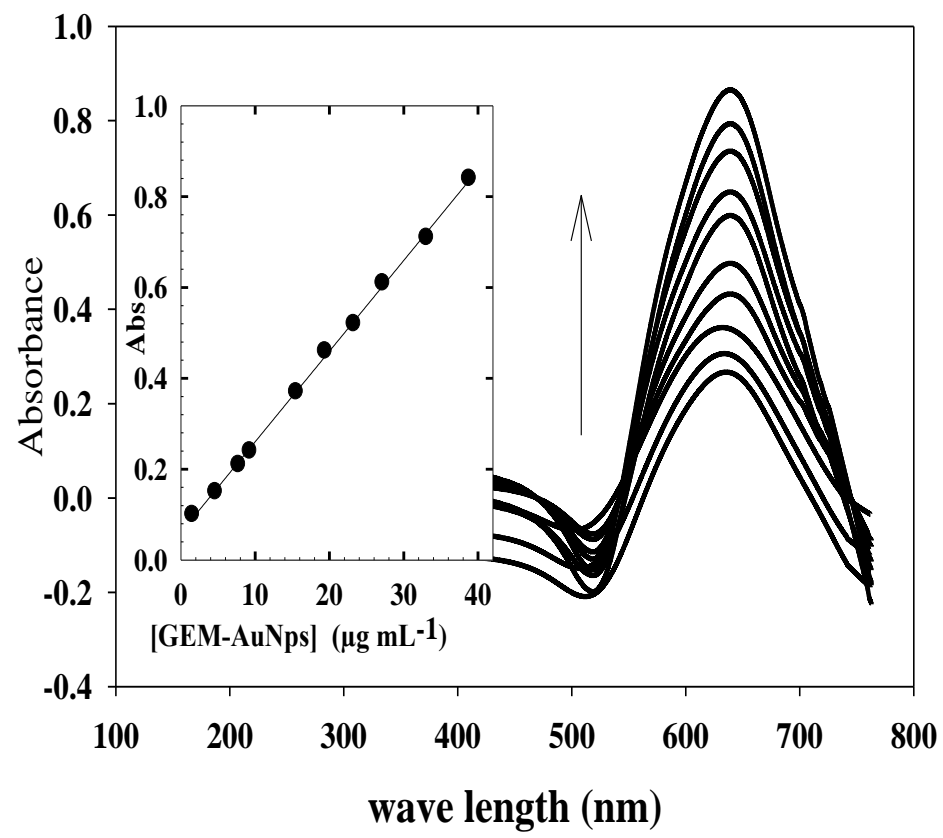

Fig. 4:- Effect of increasing the complex concentration.

Inset: Calibration curve of GEM-AuNps complex.

The apparent molar absorptivity and Sandell's sensitivity were also calculated as per their standard formula as given below. Molar absorptivity can be evaluated from the following equation.

Molar absorptivity $=$ Slope $\times$ molecular weight $\times 1031 / \mathrm{mol} \mathrm{cm}$. 
Sandell's index characterizes the number of micro- or nanograms of the determinant per millilitre of a solution with an absorbance of 0.002 for the cell path length of $1 \mathrm{~cm}$ and can express and compare the sensitivities of spectrophotometric methods (Motwani et al 2007; Raut et al 2010).

Sandell's sensitivity= Molecular weight /Molar absorptivity

All the analytical parameters of the calibration curve are listed in table 1.

Table 1:- Analytical parameters of the calibration curve

\begin{tabular}{|l|l|}
\hline Parameters & Complex \\
\hline$\lambda_{\max }(\mathrm{nm})$ & 650 \\
\hline Beer's law limits $\left(\mu \mathrm{g} \mathrm{mL}^{-1}\right)$ & $1.5-38.8$ \\
\hline Molar absorptivity $\left(\mathrm{L} \mathrm{mol}^{-1} \mathrm{~cm}^{-1}\right)$ & $0.1 \times 10^{4}$ \\
\hline Sandell sensitivity $\left(\mu \mathrm{g} \mathrm{cm}^{-2}\right)$ & 0.0038 \\
\hline Slope of regression line $(\mathrm{b})$ & 0.02 \\
\hline Intercept of regression line $(\mathrm{a})$ & 0.06 \\
\hline Correlation coefficient $(\mathrm{r})$ & 0.9998 \\
\hline Relative standard deviation & 0.5 \\
\hline LOD $\left(\mu \mathrm{g} \mathrm{mL}^{-1}\right)$ & 0.21 \\
\hline LOQ $\left(\mu \mathrm{g} \mathrm{L}^{-1}\right)$ & 0.71 \\
\hline
\end{tabular}

\section{Precision and accuracy:-}

Three different concentrations of GEM were organized and five replicate determinations were performed using standard addition method. In this method, standard drug was added with three different amounts i.e. 50\%, $100 \%$ and $150 \%$ to known pre-analyzed sample solution. By using the proposed methods the total concentrations were determined. The $\%$ recovery of added drug was calculated as:

$\%$ Recovery $=$ Amount of drug found /Amount of drug added $\times 100$

The results obtained in table 2 prove that the method is precise and accurate.

Also the mean calculated relative standard deviation values (RSD) varied from 0.5 - 0.89, indicating good repeatability of the proposed method.

Table 2:- Precision and accuracy measurements of the proposed method

\begin{tabular}{|l|l|l|l|l|l|l|}
\hline Method & Taken & found \pm SD $^{\mathbf{a}}$ & Recovery (\%) & RSD (\%) & S.E $^{\mathbf{b}}$ & C.L $^{\mathbf{c}}$ \\
\hline GEM-AuNps & 7.76 & $7.766 \pm 0.03$ & 100.07 & 0.50 & 0.0174 & $7.766 \pm 0.048$ \\
& 15.52 & $15.43 \pm 0.13$ & 99.42 & 0.89 & 0.0618 & $15.43 \pm 0.171$ \\
Mean & 23.28 & $23.3 \pm 0.20$ & 100.08 & 0.85 & 0.0900 & $23.2 \pm 0.250$ \\
\end{tabular}

${ }^{\mathrm{a}}$ Mean \pm standard deviation of five determinations.

${ }^{\mathrm{b}}$ Standard error $=\mathrm{SD} /(\mathrm{N})^{1 / 2}$.

${ }^{\mathrm{c}}$ Confidence limits at $\mathrm{P}=0.05$ and four degrees of freedom, $\mathrm{t}=2.776$

\section{Robustness and ruggedness:-}

The robustness of the method was confirmed by examining the same sample by varying parameters like reagent volume (AuNps) and reaction time. The ruggedness of the proposed method was evaluated by applying the developed procedure to assay of GEM using the same instrument by two different analysts under the same optimized conditions at different days. Since there was no significant difference between the results obtained for recovery \pm SD\% were $99.92 \pm 0.63 \%$ and $99.89 \pm 0.76 \%$ by the two analysts, respectively, the proposed method may be considered rugged.

Application to Pharmaceutical Formulations:-

The proposed method was applied for the analysis of pharmaceutical formulations of GEM as: factive tablets with AuNps. The recovery of the proposed method was presented in table 3. The assay of the pharmaceutical formulations with gold Nps were compared with the reported method (Charan and Satyabrata, 2011). Comparison of the proposed and reported methods was performed concerning the accuracy and precision using the Student's t- and F-tests (Table 4). The results prove that there is no significant difference between the proposed methods and the reported method. 
Table 3:- Recovery of Factive tablets (standard addition method)

\begin{tabular}{|l|l|l|l|}
\hline Tablet & Taken & proposed method \\
\cline { 3 - 4 } & $\left(\boldsymbol{\mu g} \mathbf{~ m L}^{-\mathbf{1}}\right)$ & Added $\left(\boldsymbol{\mu g} \mathbf{~ m L}^{-1}\right)$ & Recovery $\pm \mathbf{R S D}^{\mathbf{a}} \mathbf{( \% )}$ \\
\hline Factive (320mg) & 10 & 5 & $99.96 \pm 0.18$ \\
& 10 & 10 & $100.07 \pm 0.077$ \\
& 10 & 20 & $100.04 \pm 0.049$ \\
Mean & 10 & 30 & $99.98 \pm 0.025$ \\
& & & $100.01 \pm 0.082$ \\
\hline
\end{tabular}

${ }^{\mathrm{a}}$ Mean \pm relative standard deviation of five determinations.

Table 4:- Statistical analysis of the data for Factive tablets compared with reported method

\begin{tabular}{|l|l|l|l|}
\hline Tablet & Statistical Values & Methods \\
\cline { 3 - 4 } & & AuNps & Reported method \\
\hline Factive (320mg) & Mean $\pm \mathrm{SD}(\%)^{\mathrm{a}}$ & $99.80 \pm 0.20$ & $99.5 \pm 0.34$ \\
& $\mathrm{~N}$ & 5 & 5 \\
& $\mathrm{t}^{\mathrm{b}}$ & 1.7 & $(2.306)^{\mathrm{b}}$ \\
& $\mathrm{F}^{\mathrm{b}}$ & 2.89 & $(6.39)^{\mathrm{b}}$ \\
\hline
\end{tabular}

${ }^{\mathrm{a}}$ Mean \pm standard deviation of five determinations.

${ }^{\mathrm{b}}$ Theoretical values of t- and F-tests at $P=0.05$ are 2.306 and 6.39 , respectively

\section{Microbial activity:-}

Determination of the antibacterial activity of AuNps, GEM and GEM-AuNps complex was performed by the standard disc diffusion method against the different standard bacterial strains. After incubation for 24 hours, each plate was examined. The diameters of the zones of growth inhibition were measured. As shown in figure 5 and table 5, AuNps disks showed no inhibition zones against the tested bacterial strains. The complex produced higher antibacterial activity than GEM against Staphylococcus aureus, Micrococcus luteus, Escherichia coli, Salmonella typhimurium, Klebsiella pneumonia and Pseudomonas aeruginosa. Drugs coated with AuNps are effective against both Gram positive and Gram negative bacterial organisms, due to the small size of the nanoparticles, large surface area and high penetrating power, therefore more number of GEM molecules can be adsorbed on AuNps surfaces making them as one group improving the antimicrobial activity.
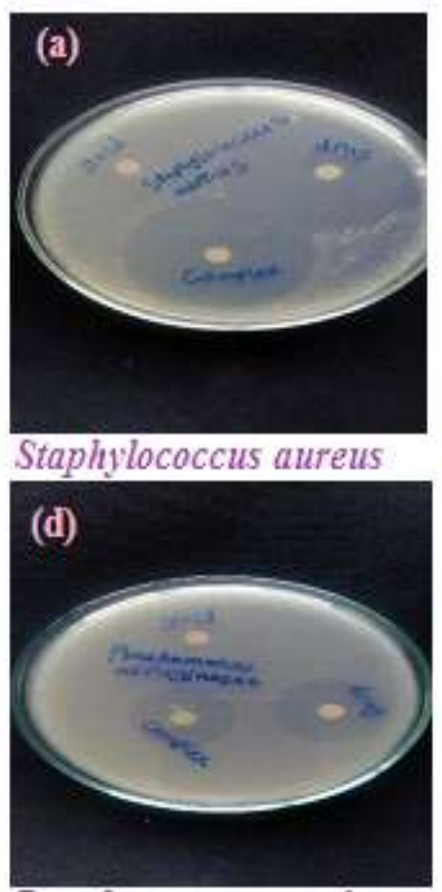

Pseudomonas aeruginosa

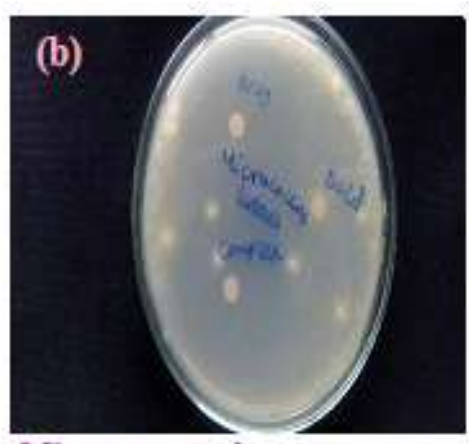

Micrococcus luteus

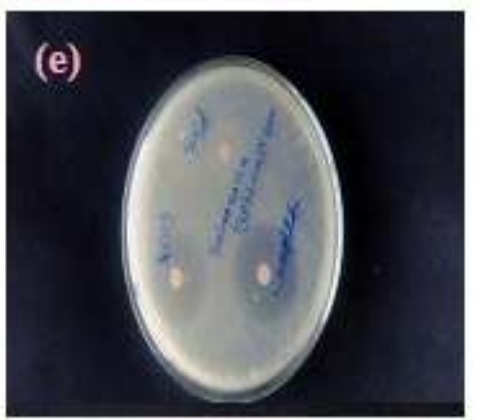

Salmonella typhimurium

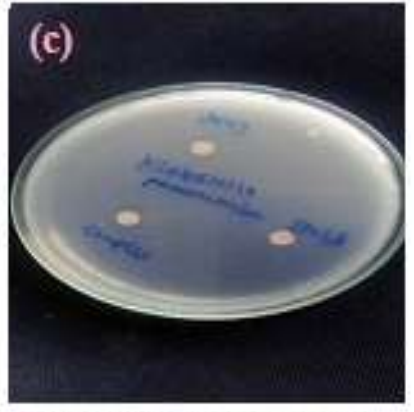

Klebsiella pneumonia

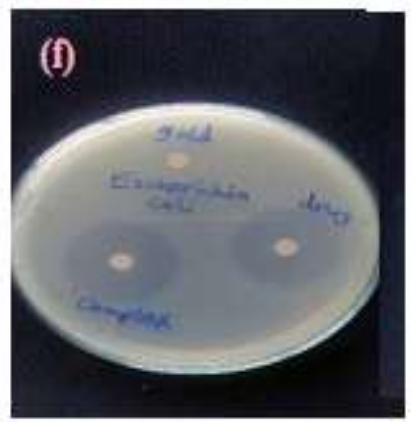

Escherichia coli

Fig 5:- Images of the petri dishes showing the antibacterial activity of AuNps, GEM and GEM-AuNps complex. 
Table 5:- Antibacterial activity of AuNps, GEM and the complex using the standard disk diffusion method against the different standard bacterial strains

\begin{tabular}{|c|c|c|c|c|c|c|}
\hline & \multicolumn{6}{|c|}{ Diameter (mm) of inhibition zones against the corresponding standard bacterial strains } \\
\hline & \multicolumn{2}{|c|}{ Gram-positive bacteria } & \multicolumn{4}{|c|}{ Gram-negative bacteria } \\
\hline & $\begin{array}{l}\text { Staphylococcus } \\
\text { aureus } \\
\text { ATCC } 6538\end{array}$ & $\begin{array}{l}\text { Micrococcus } \\
\text { luteus } \\
\text { ATCC } 10240\end{array}$ & $\begin{array}{l}\text { Escherichia } \\
\text { coli } \\
\text { ATCC } 10536\end{array}$ & $\begin{array}{l}\text { Salmonella } \\
\text { typhimurium } \\
\text { ATCC 14028 }\end{array}$ & $\begin{array}{l}\text { Klebsiella } \\
\text { pneumonia } \\
\text { ATCC 27736 }\end{array}$ & $\begin{array}{l}\text { Pseudomonas } \\
\text { aeruginosa } \\
\text { ATCC } 9027\end{array}$ \\
\hline AuNps & $\begin{array}{l}\text { No inhibition } \\
\text { zone }\end{array}$ & $\begin{array}{l}\text { No inhibition } \\
\text { zone }\end{array}$ & $\begin{array}{l}\text { No inhibition } \\
\text { zone }\end{array}$ & $\begin{array}{l}\text { No inhibition } \\
\text { zone }\end{array}$ & $\begin{array}{l}\text { No inhibition } \\
\text { zone }\end{array}$ & $\begin{array}{l}\text { No inhibition } \\
\text { zone }\end{array}$ \\
\hline GEM & 47 & 45 & 28 & 26 & 10 & 28 \\
\hline Complex & 48 & 47 & 30 & 28 & 12 & 29 \\
\hline
\end{tabular}

\section{Conclusion:-}

The proposed analytical method is simple and sensitive. It can be used for the routine analysis of GEM in bulk and pharmaceutical formulations. This method does not require any pre-treatment of the drug. It was shown that a combination of Gemifloxacin with gold nanoparticles has an effective antibacterial efficiency against various strains of Gram positive and Gram negative bacteria. This study proposed that gold nanoparticles could act as an effective drug carrier in drug delivery system. The data presented in the manuscript demonstrate that the proposed method is accurate and precise.

\section{References:-}

1. Krishna MV, Sankar DG: Utility of $\sigma$ and $\pi$-acceptors for the spectrophotometric determination of gemifloxacin mesylate in pharmaceutical formulations. Journal of Chemistry 2008, 5(3):493-498.

2. Lowe MN, Lamb HM: Gemifloxacin. Drugs 2000, 59(5):1137-1147.

3. Lomaestro BM: Gemifloxacin: A broad-spectrum oral quinolone for treatment of respiratory and urinary tract infections. Formulary 2000, 35(12):961-961.

4. Doyle E, Fowles S, McDonnell D, McCarthy R, White S: Rapid determination of gemifloxacin in human plasma by high-performance liquid chromatography-tandem mass spectrometry. Journal of Chromatography B: Biomedical Sciences and Applications 2000, 746(2):191-198.

5. Rote A, Pingle S: Reverse phase-HPLC and HPTLC methods for determination of gemifloxacin mesylate in human plasma. Journal of Chromatography B 2009, 877(29):3719-3723.

6. Cho SI, Shim J, Kim M-S, Kim Y-K, Chung DS: On-line sample cleanup and chiral separation of gemifloxacin in a urinary solution using chiral crown ether as a chiral selector in microchip electrophoresis. Journal of Chromatography A 2004, 1055(1):241-245.

7. Vinodhini C, Chitras K, Annie A, Marbaniang I, Singh A, Ashok D, Reddy C: Determination of gemifloxacin in tablets by reverse phase high performance liquid chromatography. Indian Drugs 2009, 46:71-73.

8. Krishna MV, Sankar DG: Spectrophotometric determination of gemifloxacin mesylate in pharmaceutical formulations through ion-pair complex formation. Journal of Chemistry 2008, 5(3):515-520.

9. Chen Y-H, Tsai C-Y, Huang P-Y, Chang M-Y, Cheng P-C, Chou C-H, Chen D-H, Wang C-R, Shiau A-L, Wu C-L: Methotrexate conjugated to gold nanoparticles inhibits tumor growth in a syngeneic lung tumor model. Molecular pharmaceutics 2007, 4(5):713-722.

10. Jalil R, Nixon J: Biodegradable poly (lactic acid) and poly (lactide-co-glycolide) microcapsules: problems associated with preparative techniques and release properties. Journal of microencapsulation 1990, 7(3):297325.

11. Arulkumar S, Sabesan M: Biosynthesis and characterization of gold nanoparticle using antiparkinsonian drug Mucuna pruriens plant extract. Int J Res Pharm Sci 2010, 4:417-420.

12. Atta NF, Galal A, Azab SM: Gold Nanoparticles Modified Electrode for the Determination of an Antihypertensive Drug. Electroanalysis 2012, 24(6):1431-1440.

13. Salama NN, Zaazaa HE, Azab SM, Atty SA, El-Kosy NM, Salem MY: Utility of gold nanoparticles/silica modified electrode for rapid selective determination of mebeverine in micellar medium: comparative discussion and application in human serum. Ionics 2016, 22(6):957-966.

14. Atta NF, Galal A, Azab SM: Novel sensor based on carbon paste/Nafion® modified with gold nanoparticles for the determination of glutathione. Analytical and bioanalytical chemistry 2012, 404(6-7):1661-1672.

15. Atta NF, Galal A, Azab SM: Electrochemical morphine sensing using gold nanoparticles modified carbon paste electrode. Int J Electrochem Sci 2011, 6(10):5066-5081. 
16. Brust M, Schiffrin DJ, Bethell D, Kiely CJ: Novel gold-dithiol nano-networks with non-metallic electronic properties. Advanced materials 1995, 7(9):795-797.

17. Mirkin CA, Letsinger RL, Mucic RC, Storhoff JJ: A DNA-based method for rationally assembling nanoparticles into macroscopic materials. Nature 1996, 382(6592):607.

18. Demers LM, Mirkin CA, Mucic RC, Reynolds RA, Letsinger RL, Elghanian R, Viswanadham G: A fluorescence-based method for determining the surface coverage and hybridization efficiency of thiol-capped oligonucleotides bound to gold thin films and nanoparticles. Analytical chemistry 2000, 72(22):5535-5541.

19. Kim Y, Johnson RC, Hupp JT: Gold nanoparticle-based sensing of "spectroscopically silent" heavy metal ions. Nano Letters 2001, 1(4):165-167.

20. Selvaraj V, Alagar M, Hamerton I: Analytical detection and biological assay of antileukemic drug using gold nanoparticles. Electrochimica Acta 2006, 52(3):1152-1160.

21. Sharada C, Channabasavaraj K, Mani TT: Development of a spectrophotometric method for the quantitative estimation of zidovudine concentration in bulk and pharmaceutical dosage forms. KMITL Science and Technology Journal 2014, 10(1).

22. Menon SK, Mistry BR, Joshi KV, Sutariya PG, Patel RV: Analytical detection and method development of anticancer drug Gemcitabine $\mathrm{HCl}$ using gold nanoparticles. Spectrochimica Acta Part A: Molecular and Biomolecular Spectroscopy 2012, 94:235-242.

23. Selvaraj V, Alagar M: Analytical detection and biological assay of antileukemic drug 5-fluorouracil using gold nanoparticles as probe. International journal of pharmaceutics 2007, 337(1):275-281.

24. Job P: Formation and stability of inorganic complexes in solution. 1928.

25. Sommer L, Havel J, Kubáň V: Spectrophotometric studies of the complexation in solution: Univerzita JE Purkyně; 1970.

26. Atta NF, Galal A, Azab SM, Ibrahim AH: Electrochemical Sensor Based on Ionic Liquid Crystal Modified Carbon Paste Electrode in Presence of Surface Active Agents for Enoxacin Antibacterial Drug. Journal of The Electrochemical Society 2015, 162(1):B9-B15.

27. Motwani SK, Chopra S, Ahmad FJ, Khar RK: Validated spectrophotometric methods for the estimation of moxifloxacin in bulk and pharmaceutical formulations. Spectrochimica Acta Part A: Molecular and Biomolecular Spectroscopy 2007, 68(2):250-256.

28. Raut C, Gharge D, Dhabale P, Gonjari I, Hosmanib A, Hosmani A: Development and Validation of Oseltamivir Phosphate in Fluvir ${ }^{\circledR}$ by UV spectrophotometer. International Journal of PharmTech Research 2010, 2(1):363.

29. Charan DC, Satyabrata S: Simple and rapid spectrophotometric estimation of gemifloxacin mesylate in bulk and tablet formulations. International Journal of PharmTech Research 2011, 3(1):133-135. 